\title{
EXPERIMENTAL DETERMINATION OF STATIC AND DYNAMIC ELASTIC MODULI OF RC SLABS
}

\author{
Mezgeen S. Ahmed ${ }^{1}$, Abdulhameed A. Yaseen ${ }^{*}$, Yaman S. S. Al-Kamaki ${ }^{*}$ \\ and FOUAD A. MOHAMMAD** \\ "Dept. of Civil Engineering, College of Engineering, University of Duhok, \\ Kurdistan Region-Iraq \\ ${ }^{* *}$ School of Architecture Design and the Built Environment, Nottingham Trent University: \\ Nottingham, GB
}

(Accepted for Publication: December 8, 2020)

\begin{abstract}
The purpose of this paper is to experimentally determine the static (Ec) and dynamic (Ed) elastic moduli of reinforced concrete (RC) from both static and dynamic techniques. Initially, the aforementioned parameters were estimated from the concrete compressive strength of the used mix, using compressive strength machine. Subsequently, the RC slab specimens themselves were dynamically tested dynamically under free boundary conditions. Then from, the experimentally measured natural frequency, the static and dynamic moduli were determined. To check the reliability of the dynamic test for estimating the natural frequency, the intact and defected slabs were utilized. The dynamic test was performed on four RC square slab samples of dimensions $600 \mathrm{~mm} \times 600 \mathrm{~mm} \times 40 \mathrm{~mm}$. The first set, two intact slabs, is used as control specimens were prepared with no artificial voids. While, the second set, two defected slabs, is used as defected specimens. The defected slabs contained the artificial void by fixing a polystyrene block at the center of the steel reinforcement of the slabs prior to pouring concrete. In the latter technique, a RC slab specimen is hanged by using elastic ropes to approach fully free boundary conditions. The slabs were excited by an impact hammer, to induce vibration, whilst the accelerometers were employed to record the response under such excitation. Pico Scope 6 device and amplifier was used to acquire, magnify and analyze the data. In addition, MATLAB software is used to convert the time domain to the frequency domain as well as to plot Frequency Response Function (FRF). The first natural frequency is determined as the first resonant peak on the FRF plot. It is showed that the use of the first natural frequency-based method can be usefully employed to determine the dynamic modulus of elasticity of concrete. It was found that the testing sequence did not significantly affect the measured results for the obtained Ec and Ed in this study.
\end{abstract}

KEYWORDS: Static elastic modulus; Dynamic elastic modulus; Natural frequencies; Reinforced concrete; Impact hammer.

\section{INTRODUCTION}

Tn the design, construction, and maintenance of RC structures, the static modulus elasticity of concrete $(E \mathrm{c})$ and compressive strength (fc) are key parameters in determining the member force, stress, deflection of structural elements under service conditions (Mehta, 2013 and ASTMC666, 2015). Since Ec and $\mathrm{fc}$ parameters are indicators of concrete deterioration, they have been utilized to examine the conditions of structures. Destructive tests such as compressive strength have been widely used to attain information on the elastic properties of concrete such as Ec. The concrete core specimens, which are extracted from the existing concrete structural members, are typically used and tested to determine Ec and fc, according to ASTMC469/C469M-14 guidelines. However, calculating Ec from fc causes a relatively large error (Popovics, 2008).

The standard testing methods (concrete cylinders or specimen cores) for calculating Ec and fc cannot be utilized to evaluate the entire area of the model or the real structure. as a consequence, the test permissions and several specimens are needed to acquire accurate information. Moreover, the values of Ec and fc

mezgeen@uod.ac; a.yaseen@uod.ac; yaman.alkamaki@uod.a; fouad.mohammad@ntu.ac.uk

${ }^{1}$ Corresponding author: College of Engineering, University of Duhok, Kurdistan Region, Iraq 
differ at various locations, and these differences may increase with the aging of the concrete structure (Park et al., 2020). As a result, it is essential to determine $\mathrm{Ec}$ and $\mathrm{fc}$ using a nondestructive evaluation (NDE) method that can be applied without damaging the structure. There are some NDE techniques to estimate the properties of concrete including resonance frequency tests, according to ASTM C215. It is worth mentioning that the modulus of elasticity estimated by NDE techniques is typically called the dynamic modulus of elasticity, which is always greater than the static modulus of elasticity determined in accordance with ASTM C469/C469M. The non-linear behavior of concrete provides the bases for the conventionally accepted view of why $\mathrm{Ed}$ is greater than Ec, since concrete is subjected to very small strains in dynamic testing (Neville, 1997). Besides, Philleo (1955) stated that the difference between the static and dynamic moduli of elasticity of concrete is established on the fact that the heterogeneity properties of concrete affect the two moduli in different ways.

It is noteworthy that attempts reported in (Pickett, 1945; Spinner et al., 1960; Spinner and Tefft, 1961) are among the first made to measure the elastic characteristics of isotropic materials based on non-destructive vibration tests. Most of the non-destructive damage identification techniques can be classified as either local or global damage identification methods (Doebling and Farrar 1997). Ultrasonic or acoustic, magnetic field, radiography method and X-ray methods are the examples of local damage identification techniques. These methods require that the vicinity of damage is known a priori and readily accessible for testing. These two limitations cannot be guaranteed for most cases in engineering fields, such as civil or aerospace. However, the vibration-based damage identification method is an example of a global damage identification technique which is developed to overcome aforementioned limitations (Fan and Qiao, 2011).

Currently, there are many techniques to predict the elastic properties of structures made of heterogeneous materials as concrete (Lee et al., 1997), timber (Kubojima et al., 2006; Roohnia, 2014) or laminated composites (Nedelcu, 2008; Giaccu et al., 2017) involving vibration-based methods. There are extensive experiments that have been conducted on using the resonance frequency method for measuring the dynamic modulus of elasticity of steel or other materials. Some experiments have been conducted on using this method to measure the dynamic moduli of reinforced concrete beams, but few experiments have been conducted on using this technique to reinforced concrete slab specimens.

As a consequence of a lack of consensus or approval on the ideal methodology for the characterization or estimation of the modulus of elasticity, this context leads to disagreements between design engineers, builders, testing laboratories, and concrete suppliers. Therefore, it is pointed out to the urgent need for advances in the usual methodologies and standards. Aiming to promote a cheaper and easier alternative to simplify the standardization. This is due to the fact that depending on the destructive method is time-consuming for preparing the concrete cylinders and cannot be achieved without a proper concrete compressive testing machine. This paper presents a detailed methodology for the characterization of the Ed and the estimation of the Ec of concretes based on the Impulse Excitation Technique, using impact hammer. There is a dire demand to extend this technique to directly measure the dynamic elastic property of concrete slab specimens to provide researchers and design engineers a valuable tool to estimate this property. Consequently, from dynamic elastic property, the static modulus of elasticity and the concrete compressive strength can be exactly calculated. Employing this technique will allow structural designers to detect signs of deterioration if any change happens to the dynamic properties of concrete. Moreover, using this technique will also identify the extent of damage and acts to avoid the probability of the structure from the failure. Finally, the behavior of the structural members under service conditions is controlled.

\section{EXPERIMENTAL PROGRAM}

This section describes the slab specimens, test methodology of the experiments, and the way of acquiring and analyzing the data as well as extracting the natural frequencies.

\subsection{Description of RC Slabs}

Four RC slab specimens with uniform cross section of dimensions $600 \times 600 \times 40 \mathrm{~mm}$ were used for this experimental research. They were divided into two main groups (1 and 2), differentiated by the artificial defect. The first

mezgeen@uod.ac; a.yaseen@uod.ac; yaman.alkamaki@uod.a; fouad.mohammad@ntu.ac.uk

${ }^{1}$ Corresponding author: College of Engineering, University of Duhok, Kurdistan Region, Iraq 
group (i.e. Group 1) was intact condition and stated as control one for determining dynamic modulus of elasticity Ed. While, the second group was interested to check the reliability of the dynamic test for estimating the natural frequency and to study the effect of defect on dynamic modulus of elasticity. For this purpose, included flawed RC slabs where artificial flaw was induced at center of the slabs. This defect was acquired by substituting a small square block of concrete with same volume of polystyrene, $100 \times 100 \mathrm{~mm}$ in plan and $20 \mathrm{~mm}$ deep. As aforementioned that the polystyrene was concealed in the slab at the center during the casting process, as shown in Figure 1. After casting and proper curing of slabs for not less than 28 days, they were taken out of the water bath. Upon completion of curing, the slabs were left to dry for several days. This is because of ensuring the slabs were dry prior to the commencement of testing. It is worthy to note that a C30 mix according to British Standards was used for these slabs. At the same time of casting each two slab, three cubes of the dimensions $\left(100 \times 100 \times 100 \mathrm{~mm}^{3}\right)$ were cast to estimate the property of the used concrete. After proper curing, the concrete cubes were tested under the compressive strength machine.



Fig. (1): Artificial void position prior to pouring concrete.

\subsection{Experimental Preparation and Set Up}

The surface of the slab was highlighted with a grid of equally spaced locations, as seen in Figure 2. These locations are important for reading the behavior of the slab in more details. The dividing points are vibration measurement locations that stay fixed during the data collection process. In this research, two points were sufficient to capture and plot the Frequency Response Function (FRF) of the slabs. Two points were enough to properly analysis the case in term of determining the frequencies. A single drop of super-glue was adequate to apply at each point. Prior to gluing the steel stud on the slab's surface, the mating surfaces were properly prepared and cleaned. Then, a single drop of super-glue was put on the slab surface at the marked points. Subsequently, the studs were placed, with applying pressure for about a minute. It should be pointed out that a minute of waiting was enough for such glue to be hardened. After that, the accelerometers were securely mounted on the fixed studs, and they were ready to acquire the responses. After preparing and gluing the studs on positions, the slab was suspended using flat webbing slings (cable) in order to introduce free-free boundary conditions. For laboratory testing purposes, free boundary condition is one of the extremes that is most frequently employed. It is almost impossible for this test to be achieved in practice. The influence of poorly defined supports was eliminated under free-free boundary conditions (Ren and De Roeck, 2002; Ahmed and Mohammad, 2014). The experimental setup that was used in this research to carry out dynamic tests on RC square slabs is shown in Figure 3. 


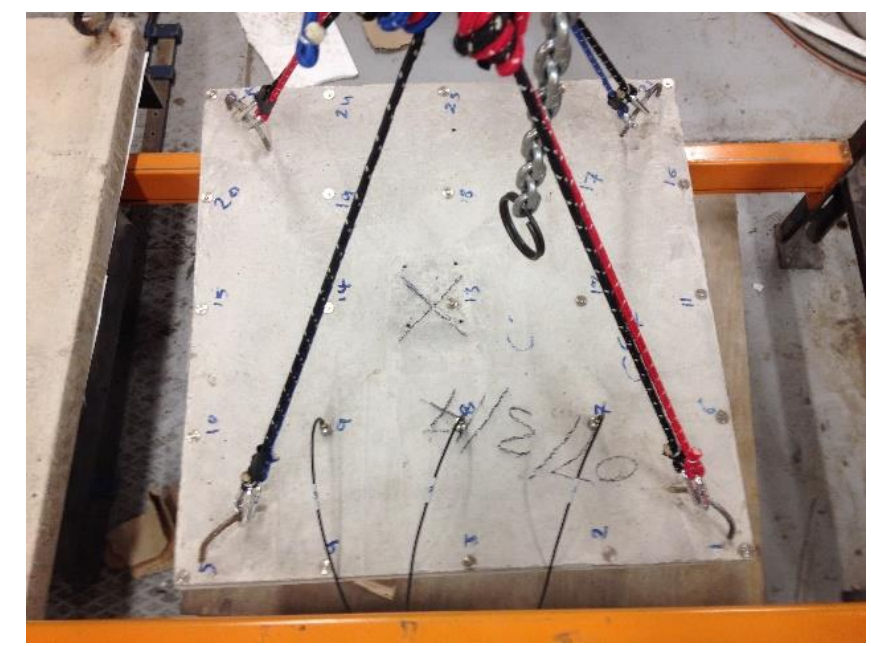

Fig. (2): Vibration grid measurement points.

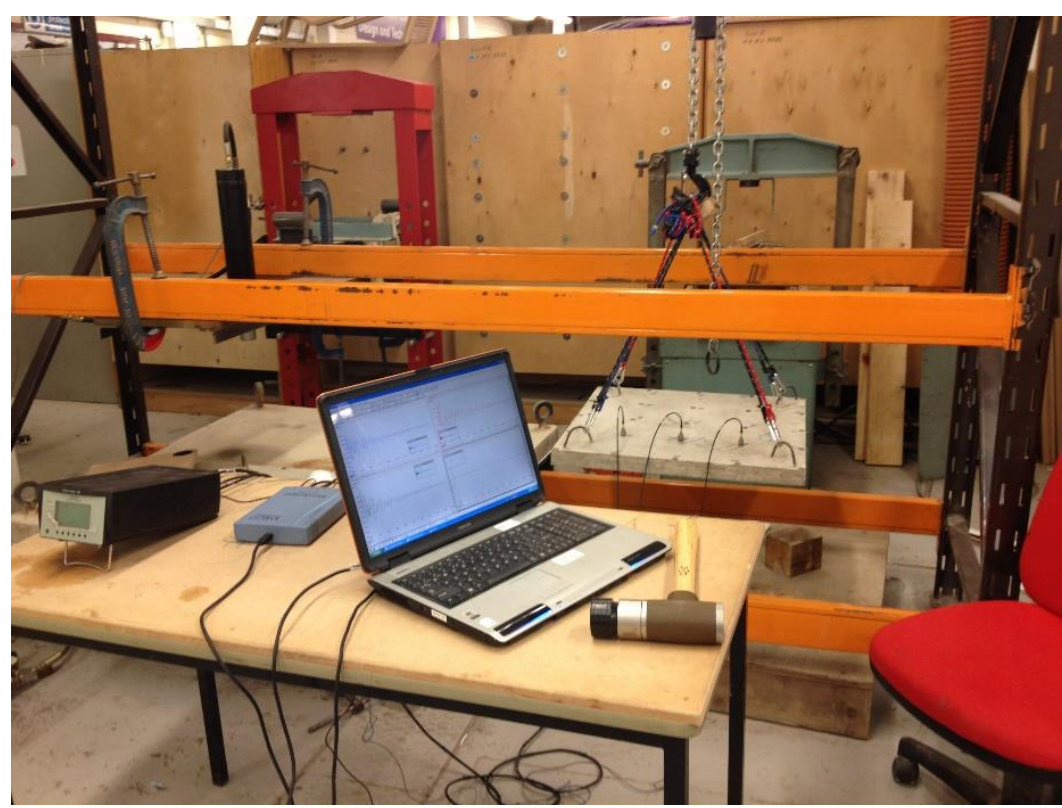

Fig. (3): Experimental test set-up.

\subsection{Experimental Measurements}

Experimental Modal Analysis EMA was adopted to measure the natural frequencies of the suspended slab. EMA consists of 3 consequent steps, namely, data acquisition, signal processing and modal parameter estimation from the obtained Frequency Response Functions (FRF).

\subsubsection{Data Acquisition}

The excitation was conducted by an impact hammer in this study to impulse the RC slab samples. This is because of the fact that impact hammer is cheaper cost and more accurate results than the vibration shaker, which is another way of excitation. Furthermore, impact hammer merely needs no more than one person to achieve the excitation with more simply moved the instrument from one point of measurement to another. The excitation was performed by using the impact hammer Brüel\&Kjær Type DeltaTron® model 8208. It is worth noting that there is a set of 4 interchangeable impact tips, force transducer, which is black, red, green, and orange-red color. These colored tips were hard, tough, medium, and soft, respectively. After some trials of using different tips, the hard (black) tip was utilized in this experiment to control the obtained frequency range of the slab. The harder the tip, which is in black, the shorter the pulse duration, and consequently the higher the frequency content (Brüel \& Kjær, 2012).

Once the specimen is excited by the tip of the impact hammer, the energy is transferred in a very little period, giving a typical input force

mezgeen@uod.ac; a.yaseen@uod.ac; yaman.alkamaki@uod.a; fouad.mohammad@ntu.ac.uk ${ }^{1}$ Corresponding author: College of Engineering, University of Duhok, Kurdistan Region, Iraq 
signal. In order to acquire the acceleration data, a piezoelectric transducer was adopted. Accelerometers are the extensively used transducers, which are employed to measure the acceleration response. Three piezoelectric accelerometers were utilized, in this experimental work, to catch the acceleration (response signals) of the specimen. The used piezoelectric accelerometers were DeltaTron ${ }^{\circledR}$ model 4514. When the response of the slabs was intended to be evaluated, the screwed accelerometers were mounted on the fixed studs. As a consequence, accelerometers were ready to obtain the response. So as to have accurate and reliable results from the dynamic tests of the RC slab, the striking hammer was frequent 5 times and the average of both excitations and responses were achieved for this experimental work. As a result, averaged FRFs were determined and then analyzed, for acquiring accurate information.

The amplifier was always utilized to boost the slight electrical signals to be fed to the data acquisition card. It is important to noted that NEXUSTM type 2690 conditioning amplifier was employed, which is comprised of eight channels, four inputs and four outputs. The impact hammer was connected to one of the amplifier input channels, where the rest three of the amplifier input channels were specified for attaching the accelerometers. It is also noteworthy that the amplifier was connected with the Data acquisition unit type Pico Scope 4424. The data is filtered into the Data acquisition unit. This is not only to eliminate the high-frequency components but also to increase the signal to noise ratio of the lower frequency components. In addition to the aforementioned function of the Data acquisition unit, the signal is transformed from analogue data to digital. Eventually, the Data acquisition unit was connected to a personal computer (PC). By using the installed Pico-scope software, the acquired analog and digital signals can be viewed and synchronized. The acquired signals were available for further process.

\subsubsection{Signal Processing}

The Personal computer with installed MATLAB, as signal processing software, was also needed to analyze and interpret the data into meaningful results. It should be noted that the captured signals from both the accelerometer and hammer at the beginning were in the time domain. Time-domain data were transferred to the frequency domain using Fast Fourier Transform (FFT) so as to gain the Frequency Response Function (FRF). Generally, the modal properties might be either extracted from the frequency domain data or directly from the time domain. However, the latter has not been used extensively for dynamic behaviour and fault identification because such data is relatively difficult to interpret (Marwala 2010). Consequently, this study relied on the frequency domain as much more preferable kind of data.

\subsubsection{Modal Parameter Extracting}

Fundamentally, a FRF is a mathematical illustration of the relationship between the input and the output of a system. By measuring the excitation force and the response acceleration in two points, the resulting frequency response function would be describing as a function of the frequency between those two points on the structure. FRF is the ratio of the obtained response to the acquired excitation signals in the frequency domain. Mathematically it can be expressed as, (McConnell and Varoto 2008). Where $H(\omega)$ is the transfer function; $X(\omega)$ is the output response at q degree of freedom; and $F(\omega)$ is the input (or forcing function) at $p$ degree of freedom

$$
H(\omega)=\frac{X(\omega)}{F(\omega)}
$$

When the striking impact hammer was hit the slab five times, the responses were acquired and analyzed. the influence of uncorrelated noise at the output was eliminated due to averaging. From the average reading, a set of frequency response function measurements were extracted. from the magnitude of averaged FRF, the natural frequencies were estimated for the slab.

\section{ANALYTICAL METHOD}

\subsection{Formulas for Predicting Modulus of Elasticity}

Generally, the modulus of elasticity increases with increasing the compressive strength of concrete. The Ec for normal weight concrete (NWC) as recommended by ACI 318-14, can be assumed as

$$
E_{c}=4700 \sqrt{f^{\prime}}
$$

mezgeen@uod.ac; a.yaseen@uod.ac; yaman.alkamaki@uod.a; fouad.mohammad@ntu.ac.uk

${ }^{1}$ Corresponding author: College of Engineering, University of Duhok, Kurdistan Region, Iraq 
Where Ec is in MPa and $f^{\prime}{ }_{c}$ is, the compressive strength of based on cylinder test at 28-days, expressed in $\mathrm{MPa}$

In the range of normal compressive strength,

BS 8110 recommends that the modulus of elasticity is approximately related to the compressive strength by

$$
E_{c}=5500 \sqrt{\frac{f_{c u}}{\gamma_{m}}}
$$

Where Ec in MPa, Fcu is, concrete compressive strength based on cube test at 28-days, in MPa and $\gamma_{m}$ is partial safety factor, which is 1.5 .

Various empirical relationships between static and dynamic moduli of elasticity were proposed by different researchers. The simplest of these, proposed by Lydon and Balendran (1986) is

$$
\mathrm{E}_{\mathrm{c}}=0.83 \mathrm{E}_{\mathrm{d}}
$$

Where both Ec and Ed are expressed in GPa.

While the British testing standard BS 8110 Part 2 provided the following empirical equation; It important to mention that both moduli are expressed in $\mathrm{GPa}$.

$$
\mathrm{E}_{\mathrm{c}}=1.25 \mathrm{E}_{\mathrm{d}}-19
$$

Where both moduli (Ec and Ed) are in GPa. However, Eq. (5) does not apply for the lightweight aggregate concrete or concretes that contain more than $500 \mathrm{~kg} / \mathrm{m}^{3}$ of cement.

\subsection{Formulas for Predicting Natural Frequencies}

The analytic closed-form formula for calculating the angular natural frequencies of a plate with the uniform cross-section under different boundary conditions is widely available in the literature (Blevins, 2001). The natural frequency of vibrations of the plate is denoted by

$$
\omega_{n}=\frac{\lambda^{2}}{l \cdot b} \sqrt{\frac{D}{\mu}}
$$

Or

$$
\begin{array}{r}
f_{n}=\frac{\lambda^{2}}{2 \pi \cdot l \cdot b} \sqrt{\frac{D}{\mu}} \\
D=\frac{E h^{3}}{12\left(1-v^{2}\right)}
\end{array}
$$

The RC slab having a length $(\ell)$, width(b), thickness (h), Poisson ratio $v$, and the mass density per unit area of plate $(\mu=\rho$ h); natural circular frequency for $\mathrm{n}$ mode, in $\mathrm{rad} / \mathrm{sec}(\omega \mathrm{n})$; natural frequency for $\mathrm{n}$ mode, in $\mathrm{Hz}(\mathrm{fn})$; and natural frequency factor, dimensionless $(\lambda)$.

\section{RESULTS AND DISCUSSIONS}

It should be emphasized that the testing sequence in this study was considered. For example, for the concrete cube specimens, the compressive strength testing was firstly performed to estimate the Fc. Subsequently, Ec and Ed were obtained. Whereas, for the RC itself, the dynamic testing was conducted to estimate the Ed and check the reliability of the technique. The calculation sequence was reversed to see if it would significantly affect the results.

Initially, a standard compressive strength was performed on the three $(100 \times 100 \times 100 \mathrm{~mm})$ cubes, for each group, to determine the actual compressive strength of the mix used in this experimental work. The target concrete compressive strength of cubes at 28 days was 30 $\mathrm{MPa}$, whilst, the actual strengths for groups 1 and 2 were $29.47 \mathrm{MPa}$ and $29.15 \mathrm{MPa}$ respectively. The average cubes concrete compressive of the two groups was 29.31MPa. This cubes average is converted to cylinder specimens average by multiplying 0.8 value (BS 1881: Part 120), which was approximately became $23.45 \mathrm{MPa}$. The static modulus of elasticity of concrete was calculated from the compressive strength of concrete cylinders, using Equation 1, and it was $22.75 \mathrm{GPa}$. The dynamic modulus of elasticity of used concrete, using the Equation 4, was 27.42 GPa. From the static modulus of elasticity, the dynamic modulus of elasticity of the concrete specimens, which represented the properties of the slab.

Subsequently, the RC slab specimens themselves were tested dynamically under freefree boundary conditions. For both 1 and 2 groups of slabs. After performing the dynamic test at least five times to ensure the repeatability of the results and to eliminate the noise, the data was acquired, magnified and converted from time domain to frequency domain. As aforementioned that using MATLAB software the FRF of groups 1 and 2 was calculated and plotted, as shown in Figure 4, 5 and 6,7, respectively.

mezgeen@uod.ac; a.yaseen@uod.ac; yaman.alkamaki@uod.a; fouad.mohammad@ntu.ac.uk ${ }^{1}$ Corresponding author: College of Engineering, University of Duhok, Kurdistan Region, Iraq 

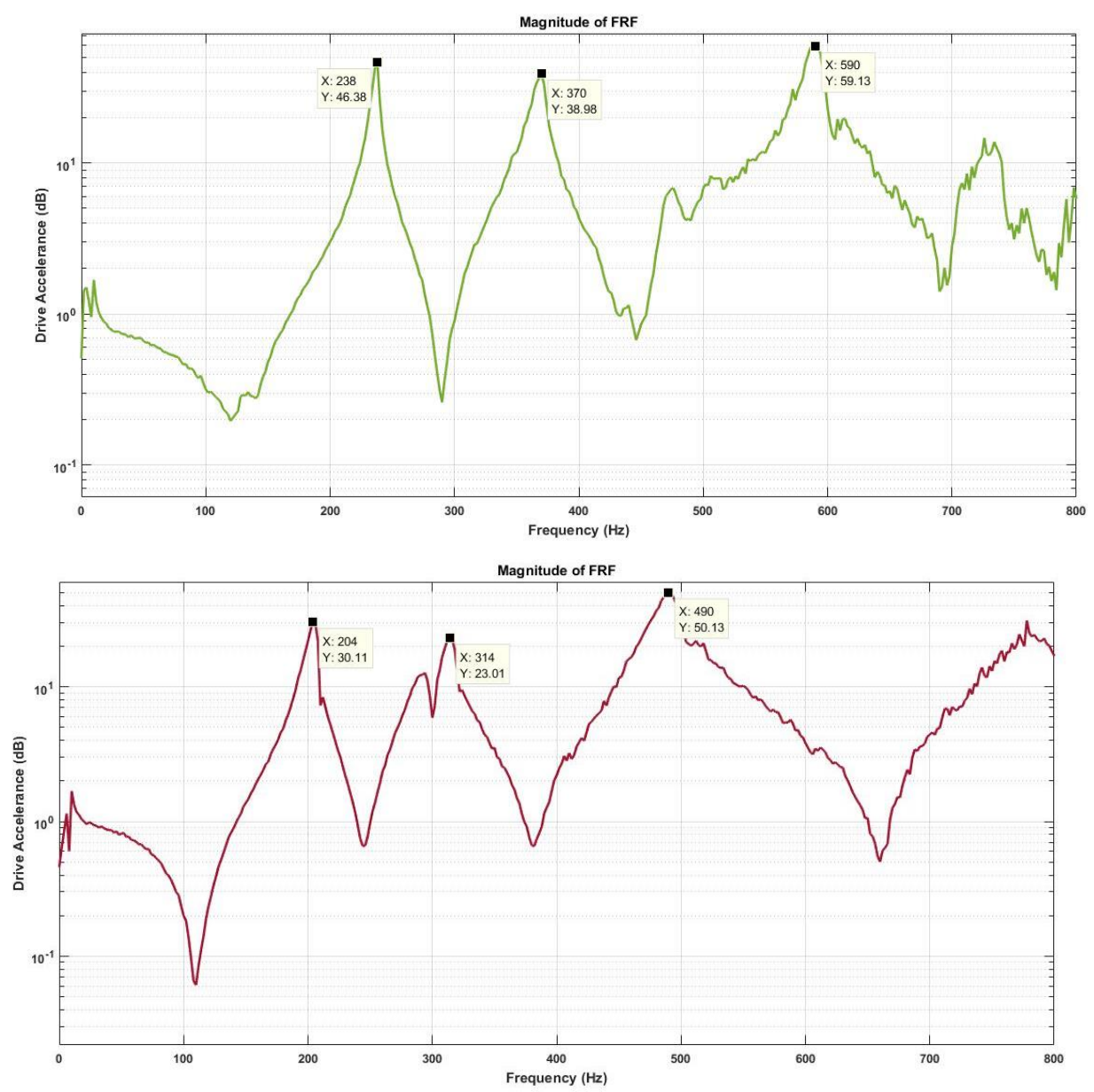

Fig. (5): Experimentally measured natural frequencies of defected $\mathrm{slab}_{1}$.

mezgeen@uod.ac; a.yaseen@uod.ac; yaman.alkamaki@uod.a; fouad.mohammad@ntu.ac.uk 


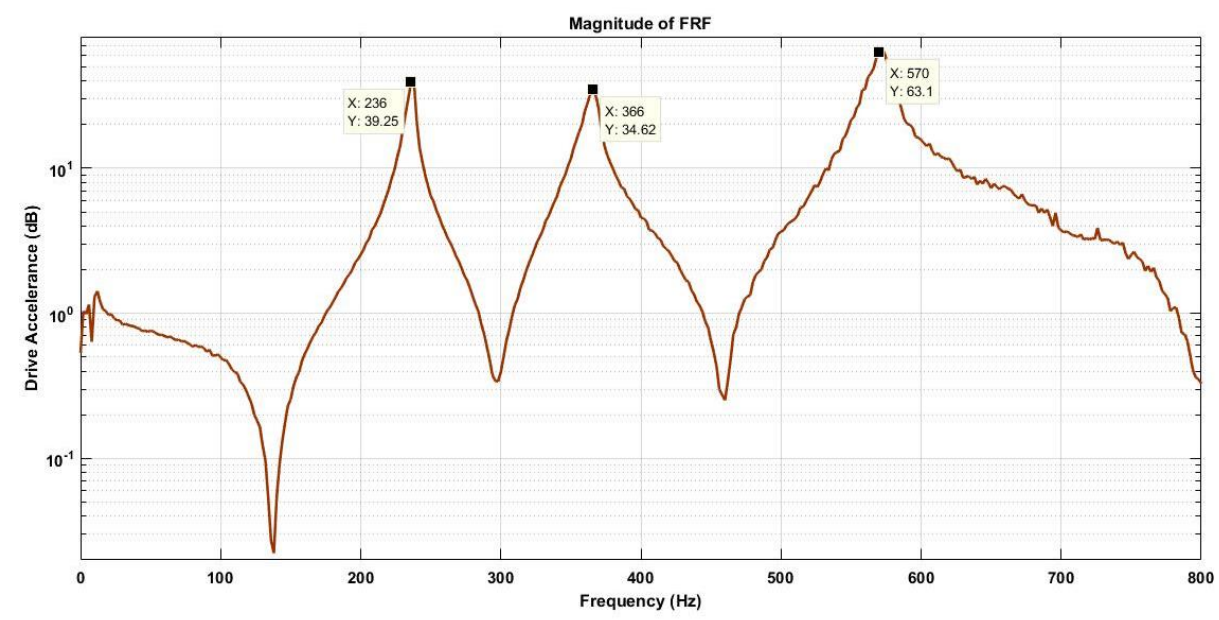

Fig. (6): Experimentally measured natural frequencies of intact $\mathrm{slab}_{2}$.



Fig. (7): Experimentally measured natural frequencies of defected $\mathrm{slab}_{2}$.

From the peaks of magnitude of FRF, natural frequencies, of the intact and defected RC specimens are individually determined and shown in Table 1, for group 1 and 2 respectively. However, the averaged natural frequencies of intact and defected slabs are shown in Figure 8. The difference between each natural frequency of intact and defected slabs are depicted in Table 2 , and graphically represented in Figure 9.

Table (1): Experimentally measured natural frequencies of intact and Defected Slabs.

\begin{tabular}{cccccc}
\hline $\begin{array}{c}\text { Slabs 1 and } \\
\mathbf{2}\end{array}$ & Intact & Defected & $\begin{array}{c}\text { Slabs 3 and } \\
\mathbf{4}\end{array}$ & Intact & Defected \\
\hline $\mathrm{F} 1(\mathrm{~Hz})$ & 238 & 204 & $\mathrm{~F} 1(\mathrm{~Hz})$ & 236 & 190 \\
\hline $\mathrm{F} 2(\mathrm{~Hz})$ & 370 & 314 & $\mathrm{~F} 2(\mathrm{~Hz})$ & 366 & 298 \\
\hline $\mathrm{F} 3(\mathrm{~Hz})$ & 590 & 492 & $\mathrm{~F} 3(\mathrm{~Hz})$ & 570 & 460 \\
\hline
\end{tabular}

mezgeen@uod.ac; a.yaseen@uod.ac; yaman.alkamaki@uod.a; fouad.mohammad@ntu.ac.uk ${ }^{1}$ Corresponding author: College of Engineering, University of Duhok, Kurdistan Region, Iraq 


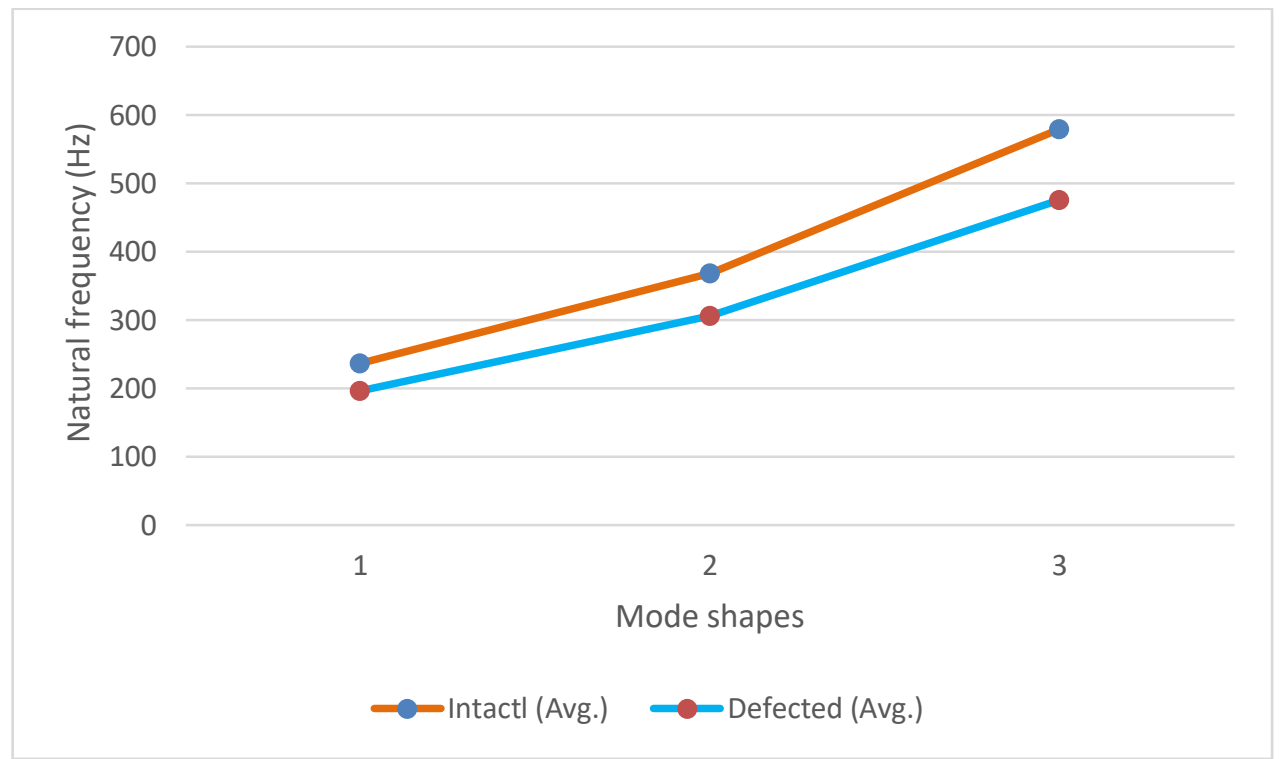

Fig. (8): Average natural frequencies of intact and defected slabs.

Table (2): Average of Experimentally measured natural frequencies of Slabs.

\begin{tabular}{cccc}
\hline Slabs & Intact (avg.) & $\begin{array}{c}\text { Defected } \\
\text { (avg.) }\end{array}$ & Reduction (Hz) \\
\hline F1 $(\mathrm{Hz})$ & 237 & 197 & 40 \\
\hline F2 $(\mathrm{Hz})$ & 368 & 306 & 62 \\
\hline F3 $(\mathrm{Hz})$ & 580 & 476 & 104 \\
\hline
\end{tabular}



Fig. (9): Reduction of natural frequencies between intact and defected slab.

In the Table 2, the compared measured natural frequencies of intact and defected slabs are compared. It is observed that there is an obvious decrease in natural frequencies of the three modes of vibrations, which is attributed to the defect and decreasing in the stiffness of the RC slabs. The change of natural frequencies increases with increasing the mode number. The reduction of natural frequencies of defected slabs with respect to the intact slabs increases due to decreasing the stiffness of the concrete material, as shown in Figure 9. The reasonable change between experimental natural frequencies of intact and defected slabs was obtained, using impulse excitation. As a consequence, the impact hammer technique is capable of precisely and reliably identifying the property and more specifically the natural frequencies of the $\mathrm{RC}$ slabs in this study.

After obtaining the reliable results using such dynamic technique, the first mode natural frequency of intact slabs, which was extracted

mezgeen@uod.ac; a.yaseen@uod.ac; yaman.alkamaki@uod.a; fouad.mohammad@ntu.ac.uk

${ }^{1}$ Corresponding author: College of Engineering, University of Duhok, Kurdistan Region, Iraq 
from the first peak of FRF, is employed in Equations (6-8) to calculate the dynamic modulus of elasticity as reported in Table 3 . The static modulus Ec and concrete compressive strength of cylinders Fc were back-calculated considering that we have a slab subjected to a dynamic test with a free-free boundary condition.

Table (3): Concrete compressive strength and modulus of elasticity.

\begin{tabular}{cccc}
\hline Technique & Fc MPa & Ec GPa & Ed GPa \\
\hline Concrete compressive Strength & 23.45 & 22.75 & 27.42 \\
\hline Impact Hammer & 22.33 & 22.21 & 26.76 \\
\hline
\end{tabular}

From the obtained results, it is clear that the Ed using the first technique, compressive strength of concrete, is about $2.4 \%$ higher than Ed using the second method, impulse excitation technique. This means that the testing sequence did not significantly affect the measured Ed and Ec for the concrete used in this study. As a results using impact hammer under free-free boundary conditions is highly recommended for laboratory testing purposes. This technique is important to be performed on the specimens themselves, when the concrete compressive strength of cubes or cylinders is forgotten to be cast with the specimens, or when the cubes or cylinders does not have the same curing of the main specimens. However, using impact hammer under free-free boundary conditions is almost impossible for this test to be achieved in practice.

\section{CONCLUSIONS}

Presented experimental research was conducted on four RC concrete slabs. Two different experimental techniques were conducted, namely impulse excitation method using the hammer, and standard compression test. Both techniques were used for the determination of Young's modulus of RC specimens, Ec and Ed. The main advantage of the dynamic Young's modulus determination using the first technique which allows for testing of the same specimen rather than preparing the concrete cubes or cylinders. In some cases, the upper and lower of the specimen are not flattened that will cause acquiring inaccurate results, static loading, or the static and dynamic Young's moduli. Furthermore, it cannot be firmly guaranteed that the members and the concrete specimens have exactly the same ingredients during casting, or have exactly the same curing process. Therefore, impact hammed is the choice to be performed in such cases.
The natural frequencies are decreased with inducing defects in RC slab specimens, using dynamic technique. Also, the estimated Ed from the impact hammer for samples in the two aforementioned exposure groups showed significant changes. The results show that using impact hammer under free-free boundary conditions is highly recommended for laboratory testing purposes. It is capable of precisely and reliably identifying the property and more specifically the Ed, Ec and Fc of the RC slabs in this study. However, using impact hammer under free-free boundary conditions is almost impossible for this test to be achieved in practice.

From the obtained results, it is clear that the Ed using the first technique, compressive strength of concrete, is about $2.4 \%$ higher than Ed using the second method, impulse excitation technique. This was achieved by performing static and dynamic testing for calculating Ed. It is found that the testing sequence did not significantly affect the measured results for the obtained Ed in this study.

\section{Acknowledgements}

The authors would like to thank the School of Architecture, Design, and the Built Environment, at Nottingham Trent University-Uk, for conducting this experiment work in its laboratory.

\section{REFERENCES}

Mehta, P.K.; Monteiro, P.J.M. (2013). ConcreteMicrostructure, Properties, and Materials, 4th ed.; McGraw-Hill Education:New York, NY, USA.

ASTMC666/C666M-15. (2015). Standard Test Method for Resistance of Concrete to Rapid Freezing and Thawing; ASTM International: West Conshohoken, PA, USA.

C469 A, (2014). Standard Test Method for Static Modulus of Elasticity and Poisson's Ratio of Concrete in Compression, West Conshohoken, $\mathrm{Pa}$, USA.

ASTM C215-14. (2016). Standard Test Method for

mezgeen@uod.ac; a.yaseen@uod.ac; yaman.alkamaki@uod.a; fouad.mohammad@ntu.ac.uk ${ }^{1}$ Corresponding author: College of Engineering, University of Duhok, Kurdistan Region, Iraq 
Fundamental Transverse, Longitudinal, and Torsional Resonant Frequencies of Concrete Specimens, West Conshohoken, Pa, USA.

Popovics, J.S. (2008). A study of static and dynamic modulus of elasticity of concrete. In ACI-CRC Final Report; American Concrete Institute: Farmington Hills, MI, USA.

Park, J., et al. (2020). "Prediction of Static Modulus and Compressive Strength of Concrete from Dynamic Modulus Associated with Wave Velocity and Resonance Frequency Using Machine Learning Techniques." Materials 13: 2886.

Neville, A.M. (1997) Properties of Concrete 4th Ed. John Wiley \& Sons Inc., New York.

R. E. Philleo, (1955). Comparison of results of three methods for determining Young's modulus of elasticity of concrete," Journal of the Americal Concrete Institute, vol. 26, no. 5, pp. 461-469.

American Concrete Institute. (2014). Building code requirements for structural concrete (ACI 31814) and commentary on building code requirments for structural concrete (ACI 318R-14). Michigan: American Concrete Institute.

Lydon, F., D. and Balendran, R., V. (1986). Some observations on elastic properties of plain concrete, cement and concrete research, 16, no. 3, pp. 314-24.

British Standards, (1997). Structural use of concrete: code of practice for design and construction, BS 8110, BSI, London.

Pickett G. (1945). Equations for computing elastic constants from flexural and torsional resonant frequencies of vibrating prisms and cylinders ASTM Proc. 45 846-865.

Spinner S, Reichard T W and Tefft W E (1960). A Comparison of Experimental and Theoretical Relations Between Young's Modulus and the Flexural and Longitudinal Resonance Frequencies of Uniform Bars, J. Res. NBS A Phys. Ch. 64A (2)

Spinner S and Tefft W E (1961). A Method for Determining Mechanical Resonance Frequencies and for Calculating Elastic Moduli from These Frequencies ASTM Proc. 61 1221-1238.

Doebling, S.W., Farrar, C.R., Prime, M.B. and Shevitz, D.W. (1996). Damage Identification and Health Monitoring of Structural and Mechanical Systems from Changes in their
Vibration Characteristics: A Literature Review. Los Alamos National Laboratory report, (LA13070-MS).

Fan, W., and Qiao, P. (2011). Vibration-based damage identification methods: a review and comparative study. Structural Health monitoring, 10(1), pp.83-111.

Lee K M, Kim D S and Kim J S (1997). Determination of Dynamic Young's Modulus of Concrete at Early Ages by Impact Resonance Test, KSCE J. Civ. Eng. 1(1) 11-18.

Roohnia M (2014). An Estimation of Dynamic Modulus of Elasticity in Cantilever Flexural Timber Beams Drvna Industrija 65(1) 3-10

Kubojima Y, Tonosaki M and Yoshihara H (2006). Young's modulus obtained by flexural vibration test of a wooden beam with inhomogeneity of density, J. Wood Sci. 52 2024.

Giaccu G F, Meloni D, Valdès M and Fragiacomo M (2017). Dynamic determination of the modulus of elasticity of maritime pine crosslaminated panels using vibration methods, WIT Trans. on Ecology and the Envir. 226571 -579 .

Nedelcu D, Gillich G R, Cziple F, Ciuca I and Padurean I (2008). Considerations about using polymers in adaptive guardrails construction Mater. Plast. 45(1) 47-52.

Ahmed, M.S. and Mohammad, F.A. (2014) Theoretical Modal Analysis of Freely and Simply Supported RC Slabs. International Journal of Mechanical, Aerospace, Industrial and Mechatronics Engineering, 8, 2026-2030.

Ren, W.X., De Roeck, G., (2002), Structural Damage Identification Using Modal Data, I: Simulation Verification, ASCE, Journal of Structural Engineering, Vol. 128, No. 1.

Brüel \& Kjær. (2012). Product data-Heavy Duty Impact Hammers - Type 8207, 8208 and 8210; Brüel \& Kjær Sound and Vibration Measurement A/S: Nærum, Denmark.

Marwala, T. (2010). Finite element model updating using computational intelligence techniques. Springer-verlag, London, UK.

Blevins, R., D. (2001). Formulas for natural frequency and mode shape, krieger pub.

BS 1881: Part 120, 1983, "Method of Determination of the Compressive Strength of Concrete Cores", Magazin of Concrete Research 27(92), pp

161-170. 